\title{
Digestibilidade do extrato de leveduras em frangos de corte ${ }^{1}$
}

\author{
Vanessa Karla Silva², Lizandra Amoroso², Ellen Hatsumi Fukayama ${ }^{2}$, Leilane Rocha Barros \\ Dourado $^{2}$, Vera Maria Barbosa de Moraes $^{3}$
}

\author{
1 Projeto financiado parcialmente pela empresa Alltech do Brasil Agroindustrial Ltda e pela FAPESP \\ ${ }^{2}$ Doutorando da FCAV-UNESP/Jaboticabal. Bolsista CNPq. \\ ${ }^{3}$ Departamento de Zootecnia da FCAV-UNESP/Jaboticabal.
}

\begin{abstract}
RESUMO - O objetivo neste trabalho foi determinar a composição química e de energia metabolizável e os coeficientes de digestibilidade da matéria seca, proteína bruta e dos aminoácidos contidos no extrato de leveduras fornecido para frangos de corte. Dois ensaios de metabolismo foram conduzidos: no primeiro ensaio, foram utilizados 200 frangos de corte machos Cobb- $500^{\circledR}$ com 14 dias de idade alojados em baterias metálicas, distribuídos em delineamento inteiramente casualizado em grupos de 10 aves por unidade experimental. Utilizou-se o método de coleta total para determinar a energia metabolizável aparente (EMA) e aparente corrigida pelo balanço de nitrogênio (EMAn) e os coeficientes de digestibilidade aparente da matéria seca e da proteína bruta. No segundo ensaio, foi utilizado o método da alimentação forçada em oito galos cecectomizados para determinação do coeficiente de digestibilidade dos aminoácidos. O delineamento experimental foi em blocos casualizados repetidos no tempo, com um grupo de cinco aves recebendo o extrato de leveduras e outro com três aves mantidas em jejum para determinação das perdas endógenas de aminoácidos. Para avaliação da composição química do ingrediente, foram determinados os teores de bruta (PB), matéria seca (MS), energia bruta (EB) e aminoácidos. O extrato de leveduras contém em média 92,49\% de MS, 48,07\% de PB, $4.883 \mathrm{kcal}$ de EB/kg e $2.073 \mathrm{kcal}$ de EMAn/kg e coeficientes de digestibilidade de 65,79\% da matéria seca, 65,47\% da proteína bruta e 99,42\% dos aminoácidos em frangos de corte. Os aminoácidos em maior proporção no extrato de leveduras são ácido glutâmico, leucina, ácido aspártico, alanina, prolina, lisina, valina, serina, isoleucina, glicina e treonina.
\end{abstract}

Palavras-chave: alimentação forçada, aminoácido digestível, coleta total de excretas, digestibilidade

\section{Yeast extract digestibility for broilers}

\begin{abstract}
The objective of this study was to evaluate the chemical composition, metabolizable energy, the digestibility coefficients of dry matter, crude protein and the amino acids contained in yeast extract supplied to broiler chickens. Two metabolism assays were carried out. In the first assay, 200 14-day old Cobb-500 ${ }^{\circledR}$ male broiler chickens were used kept in metallic cages in a randomized complete design in groups of 10 birds per experimental unit. The total excreta collection method was used to determine the apparent metabolizable energy (AME) and apparent corrected by the nitrogen balance (AMEn) and the apparent digestibility coefficients of the dry matter and crude protein. The second assay used the forced feeding method in eight roosters which were cecectomized to determine the amino acid digestibility coefficient. The experimental design was randomized blocks repeated in time, with a group of 5 roosters that received the yeast extract and another group of 3 fasted roosters to determine the endogenous losses of amino acids. The yeast extract contained on average $92.49 \% \mathrm{DM}, 48.07 \% \mathrm{CP}, 4.883 \mathrm{kcal} \mathrm{GE} / \mathrm{kg}$ and $2.073 \mathrm{kcal}$ EMAn/kg and digestibility coefficients of $65.79 \%$ dry matter, $65.47 \%$ crude protein and $99.42 \%$ amino acids in broilers. The largest proportion of amino acids in the yeast extract was glutamic acid, leucine, aspartic acid, alanine, proline, lysine, valine, serine, isoleucine, glycine, and threonine.
\end{abstract}

Key Words: digestibility, digestible amino acid, forced feeding, total fecal collection

\section{Introdução}

A levedura seca contém alto teor de proteína e é rica em vitaminas do complexo B, minerais e fibra dietética (Reed \& Nagodawithana, 1991), além de possuir grande diversidade de aminoácidos, principalmente lisina
(Campos Neto, 1987; Butolo, 1996; Moraes et al., 1997). Entre as substâncias que compõem a levedura, destacam-se os componentes da parede celular, como glicana, manana e quitina (Blumer, 2002). Entretanto, a qualidade das leveduras pode variar de acordo com o processo a que são submetidas (Moreira et al., 1998). 
A biomassa de leveduras pode ser utilizada tanto integralmente quanto apenas alguns de seus componentes como o extrato e parede celular. Para isso são empregadas diferentes técnicas com a finalidade de se obter o produto final desejado (Vilela et al., 2000).

O extrato de leveduras contém cerca de $40 \%$ de aminoácidos livres, 5 a $7 \%$ de nucleotídeos, além de peptídeos, minerais e vitaminas solúveis em água. Os aminoácidos predominantes são o ácido glutâmico e o aspártico, os quais contribuem para o uso do extrato de leveduras como flavorizante (Dawson, 2002), e inositol, um importante promotor de crescimento (Rutz et al., 2005).

Objetivou-se com este trabalho avaliar a composição química e energética do extrato de leveduras e determinar sua digestibilidade em frangos de corte.

\section{Material e Métodos}

Para a determinação da energia metabolizável aparente (EMA) e aparente corrigida (EMAn), e dos coeficientes de digestibilidade aparente da matéria seca (CDAMS), da proteína bruta (CDAPB) e os coeficientes de digestibilidade verdadeira dos aminoácidos (CDVAA) do extrato de leveduras, foram feitos dois ensaios biológicos, um com pintos em crescimento, empregando-se o método da coleta total de excretas; e outro com galos adultos cecectomizados utilizando-se o método da alimentação forçada. Os experimentos foram conduzidos no Setor de Avicultura do Departamento de Zootecnia da Universidade Estadual Paulista, Câmpus de Jaboticabal.

No ensaio 1 foram utilizados 200 frangos de corte com 14 dias de idade, alojados em baterias metálicas e distribuídos em delineamento inteiramente ao acaso. De acordo a metodologia de Sibbald \& Slinger (1963), um grupo de aves foi alimentado com ração-referência e outro grupo com substituição de $20 \%$ da ração-referência pelo extrato de leveduras. A ração-referência foi à base de milho e farelo de soja, formulada para conter 21,59\% de PB e $3.000 \mathrm{kcal}$ de EM/kg. Foram utilizadas 10 repetições com 10 aves para cada tratamento. O período experimental foi de sete dias, com quatro dias de adaptação e três dias de coleta total das excretas.

Para a coleta de excretas, foram instaladas bandejas metálicas previamente revestidas com plástico sob as gaiolas para evitar possíveis perdas. As coletas foram realizadas duas vezes ao dia, no início da manhã e no final da tarde. As amostras devidamente processadas e identificadas foram analisadas no Laboratório de Nutrição Animal do Departamento de Zootecnia da Universidade Estadual Paulista, Câmpus de Jaboticabal, juntamente com amostras das rações experimentais, para determinação da matéria seca, do nitrogênio total e da energia bruta, segundo metodologia descrita por Silva \& Queiroz (2002). Com base nos resultados laboratoriais, foram calculados os valores de energia metabolizável aparente (EMA), energia metabolizável aparente corrigida para balanço de nitrogênio (EMAn), coeficiente de digestibilidade aparente da matéria seca (CDAMS) e coeficiente de digestibilidade aparente da proteína bruta (CDAPB) utilizando as equações propostas por Matterson et al. (1965).

No ensaio 2, para determinação dos coeficientes de digestibilidade dos aminoácidos, foi utilizado o método da alimentação forçada descrito por Sibbald (1976) em galos cecectomizados. Foram utilizadas oito aves, cada ave correspondendo a uma unidade experimental, alojadas individualmente. O delineamento experimental foi em blocos casualizados repetidos no tempo, em duas vezes, com cinco aves recebendo extrato de leveduras e três aves em jejum para determinação das perdas endógenas e metabólicas.

Para a realização da cecectomia, adotou-se a metodologia descrita por Pupa et al. (1998). Após um período de quatro semanas da cirurgia, os galos foram submetidos a um período de jejum de 24 horas para limpeza do trato gastrintestinal. Com base na metodologia da alimentação forçada, utilizou-se funil especifico para o fornecimento de 30 g de alimento-teste, via esôfago até o papo, a fim de evitar regurgitação. O fornecimento do alimento foi realizado duas vezes no dia ( $15 \mathrm{~g}$ às $8 \mathrm{~h}$ e $15 \mathrm{~g}$ às $16 \mathrm{~h})$. $\mathrm{O}$ intervalo entre os dois testes foi de 7 dias. O período de sete dias entre os procedimentos da alimentação forçada deve-se ao fato de que são necessários 2 a 4 dias para que a mucosa intestinal se recupere das possíveis injúrias sofridas (Imondi \& Bird, 1966; Blikslager et al., 1997).

A coleta total de excretas foi realizada em intervalos de 12 horas, em bandejas revestidas com plástico, acondicionadas sob as gaiolas de cada galo, por um período de 56 horas após o fornecimento da primeira porção do alimento. Uma vez coletadas, as excretas foram acondicionadas em sacos plásticos, identificadas e congeladas. No final do período experimental, foi determinado o total de excretas produzidas, que foram secas pelo processo de liofilização.

As análises dos aminoácidos e das excretas foram realizadas no Laboratório Central da Mogiana Alimentos (LABTEC). Foram determinados os coeficientes de digestibilidade verdadeira de cada aminoácido, por meio da fórmula descrita por Rostagno \& Featherston (1977), com base nos resultados das análises de aminoácidos ingeridos e excretado e do endógeno obtido com galos em jejum. 


\section{Resultados e Discussão}

Os valores de matéria seca e energia bruta do extrato de leveduras (Tabela 1) foram semelhantes aos determinados pela empresa Alltech Agroindustrial do Brasil (2005) e por Rutz et al. (2006).

Observou-se pouca variação no teor de proteína bruta do alimento analisado em comparação ao obtido por Yamada et al. (2003), que determinaram 54,56\% de proteína bruta no extrato de leveduras originário de destilaria de álcool. Entretanto, Vilela et al. (2000), ao avaliarem a composição química do extrato de leveduras de cervejaria, encontraram $60,70 \%$ de proteína bruta. No entanto, a composição pode variar significativamente de acordo com as matérias-primas e os métodos de industrialização na obtenção do produto (Albino et al., 1992), uma vez que o extrato de leveduras pode ser originário da indústria cervejeira ou sucroalcooleira e pode passar por processo de secagem spray dry ou rolo rotativo.

O coeficiente de digestibilidade aparente da matéria seca foi de $65,79 \%$ e o da proteína bruta, $65,47 \%$ da MS. Esses valores não foram comparados, uma vez que não há dados de digestibilidade desse alimento na literatura.
Os aminoácidos presentes em maior porcentagem no extrato de leveduras foram, em ordem decrescente, ácido glutâmico, leucina, ácido aspártico, alanina, prolina, lisina, valina, serina, glicina e treonina (Tabela 2), no entanto, todos os valores foram inferiores aos encontrados por Sgarbieri et al. (1999), que desenvolveram uma técnica para fracionamento da biomassa de levedura (Saccharomyces sp.) e caracterização química das frações obtidas. Os resultados obtidos também foram inferiores aos encontrados por Vilela et al. (2000), empregando a mesma técnica para a obtenção do extrato de leveduras, e Yamada et al. (2003), que utilizaram uma adaptação de metodologias para a obtenção do extrato de leveduras. Todavia, somente os valores de ácido aspártico e metionina foram inferiores aos compilados pela empresa Alltech Agroindustrial do Brasil Ltda (2005) e por Rutz et al. (2006).

Sabe-se que o ácido glutâmico, aminoácido presente em maior quantidade no extrato de levedura, tem função palatabilizante, o que estimularia o consumo pelos animais. Assim, quanto mais cedo o estímulo da alimentação, menor a perda de peso inicial pós-eclosão, maior a taxa de crescimento e maior a uniformidade de peso das aves até 21 dias de idade (Sklan et al., 2000). Outro importante papel do

Tabela 1 - Composição química e energética do extrato de leveduras

\begin{tabular}{|c|c|c|}
\hline & Matéria natural & Matéria seca \\
\hline Matéria seca (\%) & 92,49 & 100 \\
\hline Proteína bruta (\%) & 48,07 & 51,95 \\
\hline Energia bruta (kcal/kg) & 4883 & 5276 \\
\hline Energia metabolizável aparente (kcal/kg) & 2610 & 2984 \\
\hline Energia metabolizável aparente corrigida para o balance de nitrogênio (kcal/kg) & 2073 & 2372 \\
\hline
\end{tabular}

Tabela 2 - Composição de aminoácidos totais e digestíveis e coeficientes de digestibilidade aparente e verdadeira no extrato de levedura, com base na matéria seca

\begin{tabular}{|c|c|c|c|c|}
\hline & \multicolumn{2}{|c|}{ Aminoácidos } & \multicolumn{2}{|c|}{ Coeficiente de digestibilidade } \\
\hline & Totais (\%) & Digestíveis (\%) & Aparente (\%) & Verdadeira (\%) \\
\hline Ácido aspártico & 3,58 & 3,48 & 93,47 & 96,99 \\
\hline Ácido glutâmico & 8,64 & 8,53 & 96,16 & 98,69 \\
\hline Alanina & 3,06 & 2,95 & 94,48 & 96,24 \\
\hline Arginina & 1,85 & 1,84 & 94,92 & 99,56 \\
\hline Cistina & 0,33 & 0,32 & 85,98 & 98,99 \\
\hline Fenilalanina & 1,90 & 1,86 & 94,99 & 97,78 \\
\hline Glicina & 2,03 & 2,02 & 91,41 & 99,42 \\
\hline Histidina & 0,95 & 0,94 & 94,47 & 98,74 \\
\hline Isoleucina & 2,20 & 2,13 & 94,73 & 96,76 \\
\hline Leucina & 3,62 & 3,55 & 95,58 & 98,11 \\
\hline Lisina & 2,60 & 2,57 & 93,97 & 99,11 \\
\hline Metionina & 0,49 & 0,48 & 89,93 & 98,34 \\
\hline Prolina & 2,62 & 2,60 & 92,55 & 97,91 \\
\hline Serina & 2,20 & 2,14 & 95,25 & 99,26 \\
\hline Tirosina & 0,90 & 0,88 & 93,12 & 97,54 \\
\hline Treonina & 2,03 & 1,95 & 93,30 & 98,37 \\
\hline Triptofano & 0,69 & 0,65 & 91,58 & 96,19 \\
\hline Valina & 2,52 & 2,45 & 93,84 & 94,30 \\
\hline
\end{tabular}


ácido glutâmico é sua atuação como substrato energético vital para células com rápida divisão como as células intestinais (Lacey \& Wilmore, 1990; Yi \& Allee, 2002). Essa característica é importante, uma vez que o desenvolvimento do trato gastrintestinal durante a primeira semana de vida é essencial para que o frango de corte possa expressar seu alto potencial genético para ganho de peso, permitindo que diminua o tempo necessário para atingir o peso de abate (Nitsan et al., 1991).

O extrato de leveduras também apresentou concentração elevada de prolina, glicina e serina, aminoácidos essenciais para pintos, pois nessa idade não são capazes de síntese orgânica em taxas suficientes para suportar máximo crescimento, ainda que para esses aminoácidos sejam considerados dispensáveis para animais adultos (Vieira \& Pophal, 2000). A síntese de glicina em pintos não é suficiente para atingir máximo crescimento (Baker et al., 1968). Esses aminoácidos podem ser limitantes, para pintos mantidos com dietas compostas principalmente por milho e farelo de soja e com menos de $21 \%$ de proteína (Schutte et al., 1997). A glicina é precursora de creatinina, ácido úrico e purinas. A síntese de creatinina em músculo de peito e níveis circulantes de ácido úrico inicialmente aumentam, atingindo um platô aos 14 dias de idade (Vieira \& Pophal, 2000).

\section{Conclusões}

O extrato de leveduras possui 92,49\% de matéria seca, 48,07\% de proteína bruta e, por quilograma, apresenta $4.883 \mathrm{kcal}$ de energia bruta, $2.610 \mathrm{kcal}$ de energia metabolizável aparente e $2.073 \mathrm{kcal}$ de energia metabolizável aparente corrigida para balanço de nitrogênio. Os coeficientes de digestibilidade da matéria seca são de 65,79\% da proteína bruta 65,47\% e 99,42\% dos aminoácidos. Os aminoácidos em maior percentual no extrato de leveduras são ácido glutâmico, leucina, ácido aspártico, alanina, prolina, lisina, valina, serina, isoleucina, glicina e treonina.

\section{Literatura Citada}

ALBINO, L.F.T.; ROSTAGNO, H.S.; SANT'ANNA, R. et al. Determinação dos valores de aminoácidos metabolizáveis e proteína digestiva de alimentos para aves. Revista da Sociedade Brasileira de Zootecnia, v.21, n.6, p.1059-1068, 1992.

ALLTECH AGROINDUSTRIAL DO BRASIL. NuPro ${ }^{\circledR}$ : Especificações do produto. Boletim técnico. Curitiba. 2005. 1p.

BAKER, D.H.; SUGAHARA, M.; COTT, H.M. Glycine-serine interrelationship in chick nutrition. Poultry Science, v.47, n.4, p.1376-1377, 1968.
BLIKSLAGER, A.T.; ROBERTS, C. Mechanisms of intestinal mucosal repair. Journal American Veterinary Medicine Association, v.211, n.11, p.1437-1441, 1997.

BLUMER, S.A.G. Enriquecimento com ferro leveduras Saccharomyces cerevisiae. 2002. 66f. Dissertação (Mestrado em Ciências) - Escola Superior de Agricultura Luiz de Queiroz, Piracicaba, 2002.

BUTOLO, J.E. Uso de biomassa de levedura em alimentação animal: propriedades, custo relativo a outras fontes de nutrientes. In: "WORKSHOP" — PRODUÇÃO DE BIOMASSA DE LEVEDURA: UTILIZAÇÃO EM ALIMENTAÇÃO HUMANA E ANIMAL, 1996, Campinas. Anais... Campinas: Instituto de Tecnologia de Alimentos, 1996. p.70-89.

CAMPOS NETO, O. Utilização dos subprodutos da indústria sucroalcooleira na alimentação animal. In: SIMPÓSIO SOBRE PRODUÇÃO ANIMAL, 4., 1987, Brasília. Anais... Brasília: Sociedade Brasileira de Zootecnia, 1987, p.129-152.

DAWSON, K. Not just bread and beer: new applications for yeast and yeast products in human health. In: LYONS, T.P.; JACQUES, K.A. (Eds.). Proceedings of the Annual Symposium, 18., 2002. Nottingham. Proceedings... Nottingham: University Press, 2002. p.225-232.

IMONDI, A.R.; BIRD, F.H. The turnover of intestinal epithelium in the chick. Poultry Science, v.45, n.1, p.142-146, 1966.

LACEY, J.M.; WILMORE, D.W. Is glutamine a conditionally essential amino acid? Nutrition Review, v.48, n.8, p.297-309, 1990.

MATTERSON, L.D.; POTTER, L.M.; STUTZ, N.W. et al. The metabolizable energy of feed ingredients for chickens. Research Report, v.7, n.1, p.3-11, 1965.

MORAES, V.M.B.; MURAKAMI, A.E.; ARIKI, J. et al. Levedura de vinhaça (Saccharomyces cerevisae) como fonte protéica na alimentação de frangos em crescimento e postura. ARS Veterinária, v.13, n.2 p.150-156, 1997.

MOREIRA, J.A.; MIYADA, V.S.; MENTEN, J.F.M. et al. Uso da levedura desidratada como fonte de proteína para suínos em crescimento e terminação. Revista Brasileira de Zootecnia, v.27, n.6, p.1160-1167, 1998.

NITSAN, Z., BEM-AURAHAM, G., ZOREF, Z. et al. Growth and development of the digestive organs and some enzymes in broiler chicks after hatching. British Poultry Science, v.32, n.3, p.515-523, 1991.

PUPA, J.M.R.; LEÃO, M.I.; CARVALHO, A.U. Cecectomia em galos sob anestesia local e incisão abdominal. Arquivos Brasileiros de Medicina Veterinária e Zootecnia, v.50, n.5, p.531-535, 1998.

REED, G.; NAGODAWITHANA, T.W. Yeast Technology. 2.ed. New York: Van Nostrand Reinhold, 1991. 378p.

ROSTAGNO, H.S.; FEATHERSTON, W.R. Estudo de métodos de determinação de disponibilidade de aminoácidos em pintos. Revista da Sociedade Brasileira de Zootecnia, v.6, n.1, p.64-75, 1977.

RUTZ, F.; RECH, J.L.; XAVIER, E.G. et al. Cuidados críticos na nutrição inicial de aves: Alternativas para melhorar o desempenho e o papel essencial dos nucleotídeos. In: SIMPÓSIO BRASILEIRO DA INDÚSTRIA DE ALIMENTAÇÃO ANIMAL, 2., 2005, Curitiba. Anais... Curitiba: Alltech Biotechnology, 2005, p.19-39.

RUTZ, F.; XAVIER, E.G.; RECH, J.L. et al. Os nucleotídeos são nutrientes essenciais? Níveis de inclusão e efeitos sobre o desempenho animal. In: RONDA LATINO AMERICANA DA ALLTECH, 16., 2006, Maringá. Anais... Maringá: Alltech Biotechnology, 2006, p.35-44.

SGARBIERI, V.C.; ALVIM, I.D.; VILELA, E.S.D. et al. Produção piloto de derivados de levedura (Saccharomyces sp.) para uso como ingrediente na formulação de alimentos. Brazilian Journal of Food Technology, v.2, n.5, p.119-125, 1999.

SCHUTTE, J.B.; SMINK, W.; PACK, M. Requeriment of young broiler chicks for glycine + serine. Archiv für Geflügelkunde, v.61, n.1, p.43-47, 1997. 
SIBBALD, I.R. A bioassay for true metabolizable energy in feedingstuffs. Poultry Science, v.55, n.1, p.303-308, 1976.

SIBBALD, I.R.; SLINGER, S.J. A biological assay for metabolizable energy in poultry feed ingredients together with findings which demonstrate some of the problems with the evaluation of fats. Poultry Science, v.59, p.1275-1279, 1963.

SILVA, D.J.; QUEIROZ, A.C. Análise de alimentos (métodos químicos e biológicos). 3.ed. Viçosa, MG: Universidade Federal de Viçosa, 2002. 235p.

SKLAN, D.; NOY, Y.; HOYZNAN, A. et al. Decreasing weight loss in the hatchery by feeding chicks and poults in hatching trays. Journal of Applied Poultry Research, v.9, n.1, p.142-148, 2000.
VIEIRA, S.L.; POPHAL, S. Nutrição pós-eclosão de frangos de corte. Revista Brasileira de Ciência Avícola, v.2, n.3, p.189-199, 2000.

VILELA, E.S.D.; SGARBIERI, V.C.; ALVIM, I.D. Valor nutritivo da biomassa de células íntegras, do autolisado e do extrato de levedura originária de cervejaria. Revista de Nutrição, v.13, n.2, p.127-134, 2000.

YAMADA, E.A.; ALVIM, I.D.; SANTUCCI, M.C.C. et al. Composição centesimal e valor protéico de levedura residual da fermentação etanólica e de seus derivados. Revista de Nutrição, v.16, n.4, p.423-432, 2003.

YI, G.F.; ALLEE, G.L. [2002]. Revisão de literatura glutamina (GIn) e glutamato (Glu). Disponível em: <http://www.lisina.com.br>. Acesso em: 13/2/2006. 